\title{
Gender-Dependent Effects of Thimerosal on Human Progenitor Neurons: A Potential Link to Regressive Autism
}

Gregory R. Goodwin ${ }^{1}$, Narges Sadat Shamabadi ${ }^{2}$, Pratima Pandey ${ }^{1}$, Ewen McLean ${ }^{3}$, Omar Bagasra $1, *$

1. Claflin University, South Carolina Center for Biotechnology, 400 Magnolia Street, Orangeburg, SC 29115, USA; E-Mails: grgoowdin70@gmail.com; prpandey@claflin.edu; obagasra@claflin.edu

2. Environment Research Center, University of Qom, Qom, IRAN; E-Mail: n.shamabadi@gmail.com, current address, Department of Bioengineering, Clemson University, SC, USA

3. Aqua Cognoscenti LLC, West Columbia, SC 29170, USA; E-Mail: ewen.mclean@gmail.com

* Correspondence: Omar Bagasra; E-Mail: obagasra@claflin.edu

Academic Editor: M. Glória Pereira

Special Issue: Persistent Organic Pollutants

Adv Environ Eng Res

2021, volume 2, issue 2

doi:10.21926/aeer.2102011
Received: September 26, 2020

Accepted: May 05, 2021

Published: June 07, 2021

\begin{abstract}
Regressive Autism [RA] is a subtype of autism spectrum disorder (ASD) that manifests as the loss of previously acquired developmental milestones and skills. Early life dysregulation of neurodevelopment due to exposure to toxic metals has been associated with ASD, but the underlying biological mechanisms by which metals influence neurodevelopment remain unclear. We explored the potential role of thimerosal or ethylmercury on neurite formation and oxytocin receptor (OXTR) modulation in four human-developing neuronal cell lines of male and female origin ( $\mathrm{N}=2$ each). We exposed the cell lines to three levels of thimerosal that closely represented the concentrations an infant (equivalent to $1 \mathrm{~L}$ of blood volume), an adolescent $(\sim 5 \mathrm{~L})$, and an adult $(\sim 10 \mathrm{~L})$ might receive from multiple doses of vaccine containing $100 \mu \mathrm{g} / \mathrm{mL}$ of thimerosal. We found that exposure to vaccine-equivalent concentrations of thimerosal induced significantly greater neurite dysregulation, including central chromatolysis,
\end{abstract}

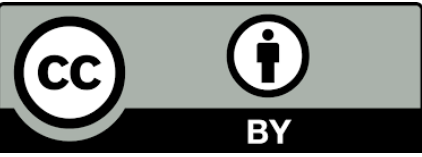

(C) 2021 by the author. This is an open access article distributed under the conditions of the Creative Commons by Attribution License, which permits unrestricted use, distribution, and reproduction in any medium or format, provided the original work is correctly cited. 
neurite abnormalities (i.e., axonal length, relative diameter, and pathways in neurons), and syncytia formation in undifferentiated and partially differentiated human developing neurons compared to controls. Exposure of male neurons to thimerosal significantly affected neurite formation and OXTR expression compared to the female neurons. In developed nations, most vaccines are thimerosal-free; nonetheless, some still incorporate ethylmercury as a preservative. In contrast, due to the lack of refrigeration in many developing nations, thimerosal is still used widely in most vaccines. Our study shows that ethylmercury induced profound neurite dysregulation and downregulated OXTR expression. The progenitor neurons from males were significantly more susceptible to thimerosal than those from females. However, internal factors in vaccine recipients may trigger dysfunction in the Blood-Brain Barrier (BBB), and screening potentially vulnerable individuals for conditions that may contribute to a BBB breach before vaccination might be beneficial.

\section{Keywords}

Autism spectrum disorder; blood-brain barrier; ethylmercury; interleukin-6 (IL-6)]; proinflammatory cytokines; regressive autism; thimerosal; tumor necrosis factor-alpha (TNF- $\alpha$ )

\section{Background}

\subsection{Regressive Autism (RA) and Autism Spectrum Disorder (ASD)}

RA is a devastating disorder affecting children between the ages of 1-3 years. The condition is sometimes characterized by a sudden onset of the loss of social interaction following otherwise healthy development $[1,2]$. Developmental regression occurs in approximately one-third of the children with ASD [3,4]. There is a strong genetic influence in the development of ASD, and hundreds of genes have been implicated. The current perception regarding RA is that this disorder may have a different etiology and pathogenesis from a neurobiological perspective $[1,4-7]$. Despite the prevalence of rising autism, current detection methods and treatment options for this disease are limited [3, 5, 7]. Although numerous scientific and well-documented studies have shown no direct links between childhood vaccinations and ASD, serious parental concerns remain regarding the safety of vaccination $[8,9]$. The organomercury compound thimerosal, which has been in use as an antibacterial and antifungal agent in many vaccines and other injectable biological products, is an important part of this debate [10]. Thimerosal is an ethylmercury-containing pharmaceutical compound comprising $49.55 \%$ mercury. It was developed in 1927 and was designed to solve the toxicity concerns of elemental mercury and mercuric chloride as a bactericide and fungicide [10, 11]. If thimerosal enters the human brain, it may be metabolized or degraded to highly toxic inorganic mercury-containing compounds that can persist for a long time [9]. However, it is not clear if thimerosal can penetrate the blood-brain barrier (BBB) in normal healthy individuals $[9,12]$. As millions of children who receive thimerosal-containing vaccines and other products that contain ethylmercury do not show apparent signs of neurotoxicity, thimerosal risks are probably minimal [13]. Indeed, primate research supports the notion that use of ethylmercury poses little risk [14]. 
Nonetheless, rigorous studies are still required to ensure that subtle effects are not encountered by a small fraction of the population.

In recent years, concerns about the possible links between immunization with thimerosalcontaining vaccines and RA development have grown [14]. Many case-control and cohort studies have been conducted on several populations, and none have confirmed a direct relation between thimerosal and increased risk of RA or ASD development [1-4, 15]. RA is a unique syndrome where an apparently healthy and normally developing child, either soon after or briefly following childhood vaccination, becomes neurologically impaired $[1-4,15]$. In this study, we examined whether thimerosal has any negative effects on developing human neurons in vitro. To demonstrate an effect or lack thereof, we employed concentrations greater than those that might be experienced by a neonate, a toddler, and a young adult after vaccination.

\section{Materials and Methods}

\subsection{Materials}

All the reagents were purchased from Sigma (Saint Louis, MO, USA). The cell culture supplies comprising Eagle's Minimum Essential Media (EMEM), Fetal Bovine Serum (FBS), and Penicillin/Streptomycin solutions were purchased from Fisher Scientific (Hanover Park, IL, USA). Neuroblastoma (NB) cell lines (CRL 2266, CRL-2149, CRL-2142, and CRL-2267) were purchased from ATCC (Manassas, VA, USA).

\subsection{Methods}

\subsubsection{Cell Culture}

Cells of male (CRL-2267 and CRL-2142) and female (CRL-2266 and CRL-2149) origin were cultured with EMEM supplemented with 10\% heat-inactivated FBS and 1\% L-Glutamine-PenicillinStreptomycin solution (complete media) at $37^{\circ} \mathrm{C}, 5 \% \mathrm{CO}_{2}$. The stock cell cultures were grown in 25 $\mathrm{mL}$ or $75 \mathrm{~mL}$ flasks (Thermo-Scientific, Nunc, Rochester, NY).

\subsubsection{Selection of Thimerosal Concentrations}

We hypothesized that when introduced in human developing neurons (HDN), thimerosal may cause neurite dysregulations at higher concentrations compared to normal concentrations, e.g., following concurrent DTaP, flu, and other vaccines, or other medications (skin test antigens, antivenins, immunological, ophthalmic and nasal formulations), in three different age groups, infants $(40 \mathrm{ng} / \mathrm{mL})$, adolescents $(20 \mathrm{ng} / \mathrm{mL})$, and adults $(10 \mathrm{ng} / \mathrm{mL})$. For this, we used the NB cell lines that mimic and represent a developing human brain in vitro [5]. To determine whether these three concentrations of thimerosal were non-cytotoxic, the NB cells were seeded in 96-well flat surface plates (Nunc) at $1 \times 10^{4}$ cells per well. The cells were incubated for $6 \mathrm{~h}$ at $37^{\circ} \mathrm{C}, 5 \% \mathrm{CO}_{2}$, allowing them to attach to the surface, and then were exposed to different concentrations of thimerosal [5]. The viability of each cell line was determined using Eosin-Y vital stain dye. The detailed experimental methods have been described previously [5]. 


\subsubsection{Hematoxylin and Eosin (H \& E) Staining}

For morphological studies, each cell line was grown in 8-well glass chamber slides with $1 \times 10^{5}$ cells (approx.) in $100 \mathrm{~mL}$ of media for five days, approximately equal to the half-life of thimerosal in the blood. For seeding the human developing neuronal cell lines, the stock cell cultures, grown in the flasks, were gently washed once with $1 x$ sterile phosphate-buffered saline (PBS; Fisher Scientific; Fair Lawn, NJ), followed by trypsinization, until a single-cell suspension was formed; trypsin was inactivated by $1 \mathrm{~mL}$ PBS. The cells were counted using a hemocytometer and adjusted to $1 \times 10^{6}$ cells $/ \mathrm{mL}$. The 8 -well chamber slides were labeled, and $100 \mu \mathrm{L}$ of cells were added to each well together with $5 \mu \mathrm{L}$ of either of the three dilutions of thimerosal [5]. After five days, the media was removed from the slides, and the cells were fixed by adding $500 \mu \mathrm{L}$ of freshly prepared $2 \%$ paraformaldehyde (PFA) to each well and allowed to incubate overnight at room temperature [5, 6]. The caskets of the glass slides were removed by the device provided by the manufacturer, and the slides were washed gently three times using $1 \times$ PBS. These slides were stained with freshly prepared H\&E (Leica Biosystems Richmond, Inc., Richmond, IL), washed in distilled water for a minute, and mounted with the mounting buffer containing 50\% PBS and 50\% glycerol. They were observed under 10X and 40X magnification and analyzed for neurite formation, i.e., central chromatolysis, axonal length, thickness, thinning, and degeneration. Additionally, syncytia formation and other morphological and cytotoxic changes were recorded for comparing to controls. The experiments were repeated at least six times and the observations were recorded using a digital camera (Olympus BX51).

\subsection{Immunocytochemistry}

Like the previous morphological studies, all cells were grown in 8-well glass chamber slides and fixed in 2\% PFA. Following overnight incubation, the cells were washed three times with $1 \mathrm{X}$ PBS and soaked with a blocking agent (2\% Bovine Serum Albumin [BSA] in 1X PBS) for 10 min. After soaking with the blocking buffer, a primary antibody $[A b]$, rabbit polyclonal Ab for oxytocin receptor was diluted (1:200) in the blocking buffer, and $100 \mu \mathrm{L}$ was added to each well. The slides were incubated at $4^{\circ} \mathrm{C}$ in humidified chambers overnight and then washed three times with $1 \mathrm{X}$ PBS. Next, in a dark environment, a goat anti-rabbit IgG $\mathrm{F}\left[\mathrm{ab}^{\prime}\right]^{2}$ antibody and FITC conjugate was used at a working dilution of $1: 40$, and $100 \mu \mathrm{L}$ of this mixture was added to each well. The slides were then incubated at $37^{\circ} \mathrm{C}$ for $1 \mathrm{~h}$ and washed three times with $1 \mathrm{X}$ PBS, allowing a 10-minute soak each time. The gaskets were then carefully removed from the glass slides with gasket removal tools without disturbing the cells and mounted using the mounting solution ( $50 \%$ glycerol and $50 \%$ PBS). The slides were then analyzed to observe the percentage of oxytocin receptor [OXTR] positive neurons in thimerosal-exposed neurons and compared to the controls $[5,6]$. Each experiment was repeated at least four times.

\subsubsection{Statistical Analysis}

All results are expressed as the mean \pm standard deviation (SD). The differences between various concentrations of thimerosal-exposed groups and the negative controls were tested using one-way analysis of variance with specific mean comparisons. Differences were considered significant at $p$ value $<0.05$. The images of the cells from experimental and control groups were compared after 
H\&E staining. They were analyzed by counting the total number of cells; neurite formation and cellular death were identified by central chromatolysis, axon elongation, degeneration, thinning, and syncytia formation. Frequency data were analyzed by chi-square test or paired Student's t-test. Statistical analyses were performed in Stata for Windows, software version 11 [5].

\section{Results}

\subsection{Neurite Formation}

We examined various morphological changes in the developing human neurons after exposure to different concentrations of thimerosal. The morphological changes included significant modulation in neurite formation, such as axonal length, axonal elongation, thinning, degeneration, and central chromatolysis of neural cells, compared to controls.

\subsection{Morphological Effect of Thimerosal on Human Developing Neurons}

As shown in Table 1 and Figure 1, CRL-2267 progenitor neurons exposed to three different concentrations of thimerosal for five days revealed a profound dysregulation in neurite formation. Briefly, Figure $1 \mathrm{~A}$ illustrates the morphological appearance of control cell lines. We used these images as a baseline reference to compare with cell lines exposed to various concentrations of thimerosal. Figures 1B-D show representative images of CRL-2267 male neuronal cell lines exposed to low, medium, and high concentrations of ethylmercury. Exposure to thimerosal induced profound neurite dysregulation, including axonal thinning, elongation, and increased chromatolysis (Table 1) compared to the baseline. Interestingly, at all three concentrations of thimerosal, cellular proliferation was significantly reduced, thus decreasing the total number of cells (Figures $1 \mathrm{C}$ and 1D). We also observed a significant increase in the size of neuronal bodies, particularly at higher concentrations of thimerosal (Figures $1 \mathrm{C}$ and 1D).

Table 1 Neurite formation in the male CRL-2267 neuroblastoma cell line after exposure to three different concentrations of thimerosal. Low (L), Medium (M), and High (H) refer to $10 \mathrm{mg}, 20 \mathrm{mg}$, and $40 \mathrm{mg}$ of thimerosal/L, respectively.

Morphological characters

\begin{tabular}{llllll}
\hline 2267 HE & Chromatolysis & Syncytia & Axon Thinning & Axon Elongation & Proliferation \\
Control & 5.90 & 0 & 18.89 & & 92.27 \\
& 8.19 & 1.90 & 16.31 & 4.42 & 50.26 \\
Low & $\mathrm{P}<0.2155$ & $\mathrm{P}<0.1778$ & $\mathrm{P}<0.2259$ & $\mathrm{P}<0.2355$ & $\mathrm{P}<0.0011$ \\
& 20.87 & 2.99 & 7.11 & 2.54 & 43.31 \\
Med & $\mathrm{P}<0.0458$ & $\mathrm{P}<0.2080$ & $\mathrm{P}<0.0079$ & $\mathrm{P}<0.7040$ & $\mathrm{P}<0.0025$ \\
& 10.21 & 3.04 & 11.59 & 1.49 & 33.85 \\
High & $\mathrm{P}<0.0019$ & $\mathrm{P}<0.0042$ & $\mathrm{P}<0.0504$ & $\mathrm{P}<0.0505$ & $\mathrm{P}<0.0018$ \\
\hline
\end{tabular}




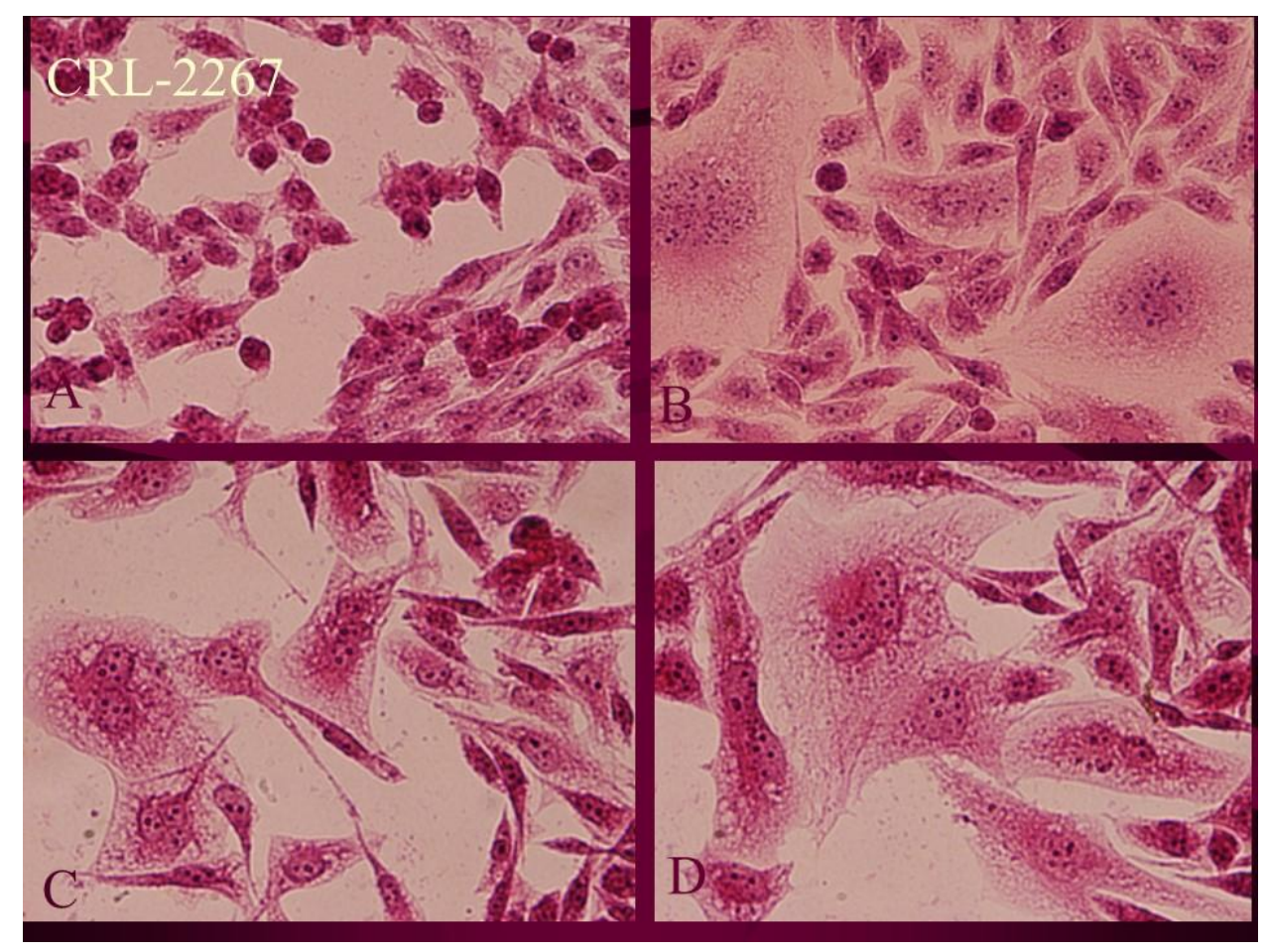

Figure 1 A-D: Morphological analyses utilizing $H \& E$ staining. Male origin human progenitor neuronal cell line (CRL-2267) was evaluated for any disruption in neurite formation after exposure to three different concentrations of thimerosal. The top left image $A$, represents the control cell lines that was not exposed to thimerosal, where as $B, C$ and $D$ represent images of cell lines exposed to $10 \mathrm{mg}, 20 \mathrm{mg}$ and $40 \mathrm{mg}$ of thimerosal, respectively.

The male progenitor cell line CRL-2142, which was relatively more differentiated than CRL-2267 [6], when exposed to the different thimerosal concentrations, showed a significant increase in chromatolysis and syncytia formation (Figure 2 and Table 2). We observed a marked increase in neurite deformation, although the changes were not statistically significant. We also noted a marked reduction in cellular proliferation (Table 2 ). 


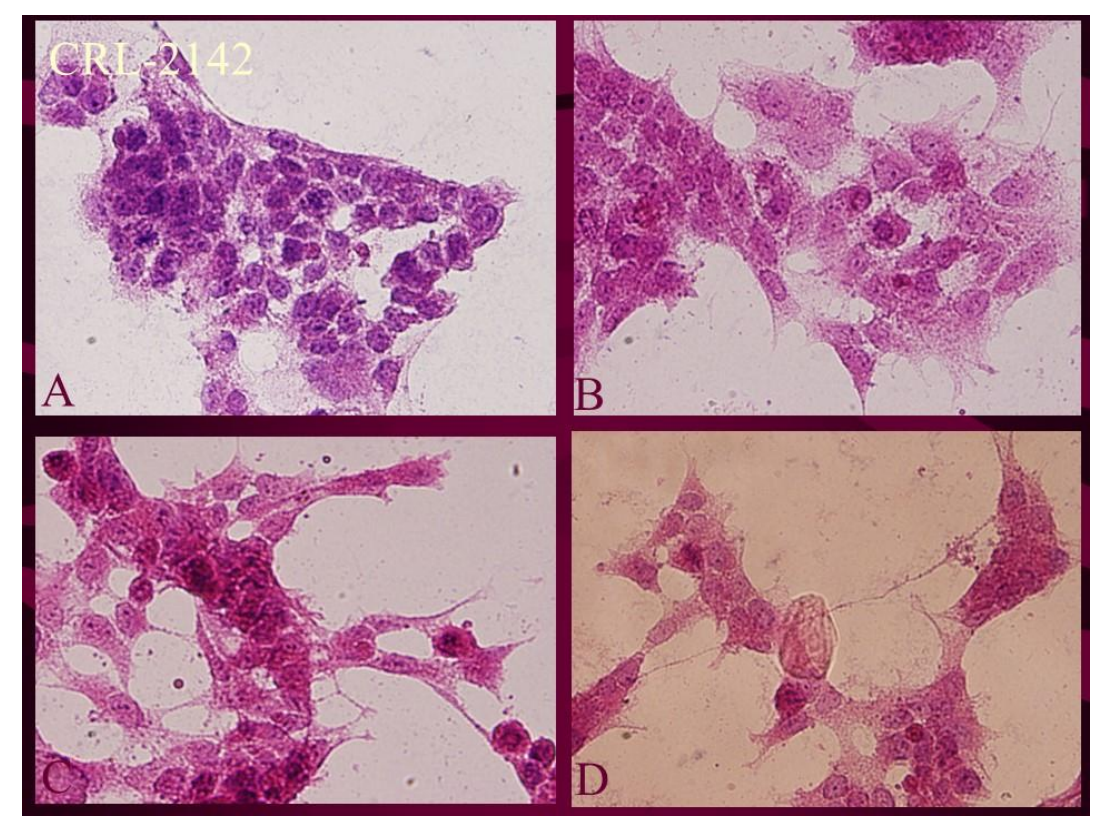

Figure 2 A-D: Morphological analyses utilizing H\&E staining. Male origin human progenitor neuronal cell line (CRL-2142) was evaluated for any disruption in neurite formation after exposure to three different concentrations of thimerosal. The top left image $A$, represents the control cell lines that was not exposed to thimerosal, where as $B, C$ and $D$ represent images of cell lines exposed to $10 \mathrm{mg}, 20 \mathrm{mg}$ and $40 \mathrm{mg}$ of thimerosal, respectively.

Table 2 Neurite formation in male CRL-2142 neuroblastoma cell line after exposure to three different concentrations of thimerosal. Low (L), Medium (M), and High (H) refer to $10 \mathrm{mg}, 20 \mathrm{mg}$, and $40 \mathrm{mg}$ of thimerosal/L, respectively.

\begin{tabular}{llllll}
\hline \multicolumn{5}{c}{ Morphological characters } \\
\hline \multirow{2}{*}{$2142 \mathrm{HE}$} & Chromatolysis & Syncytia & $\begin{array}{l}\text { Axon } \\
\text { Thinning }\end{array}$ & Axon Elongation & Proliferation \\
Control & 1.49 & 0.85 & 5.51 & 2.15 & 62.65 \\
& 2.36 & 0 & 9.89 & 3.64 & 44.88 \\
Low & $\mathrm{P}<0.1019$ & $\mathrm{P}<0.1778$ & $\mathrm{P}<0.2475$ & $\mathrm{P}<0.2892$ & $\mathrm{P}<0.1003$ \\
& 2.88 & 0.58 & 6.97 & 2.55 & 38.33 \\
Med & $\mathrm{P}<0.3165$ & $\mathrm{P}<0.3632$ & $\mathrm{P}<0.4859$ & $\mathrm{P}<0.6109$ & $\mathrm{P}<0.0810$ \\
& 5.3 & 1.92 & 9.49 & 3.14 & 36.05 \\
High & $\mathrm{P}<0.0429$ & $\mathrm{P}<0.0422$ & $\mathrm{P}<0.2180$ & $\mathrm{P}<0.8220$ & $\mathrm{P}<0.0782$ \\
\hline
\end{tabular}

The female progenitor neuronal cell CRL-2266 represented a relatively undifferentiated cell line, while CRL-2149 was relatively differentiated [6]. As shown in Figure 3 and Table 3, when exposed to thimerosal, CRL-2266 did not express significant neurite deformations as was observed in the male cell line. We observed morphological neuromodulations, including notable changes like axonal thinning, elongations, syncytia formation, and reductions in cellular proliferation; however, these were not significant (Table 3). The only significant change noted was an increase in chromatolysis 
at the highest concentration of thimerosal ( $p<0.0145$ ). Although morphological observations suggested neurite changes and reduction in cellular proliferation in the relatively differentiated cell line CRL-2149, they were not significant (Figure 4 and Table 4).

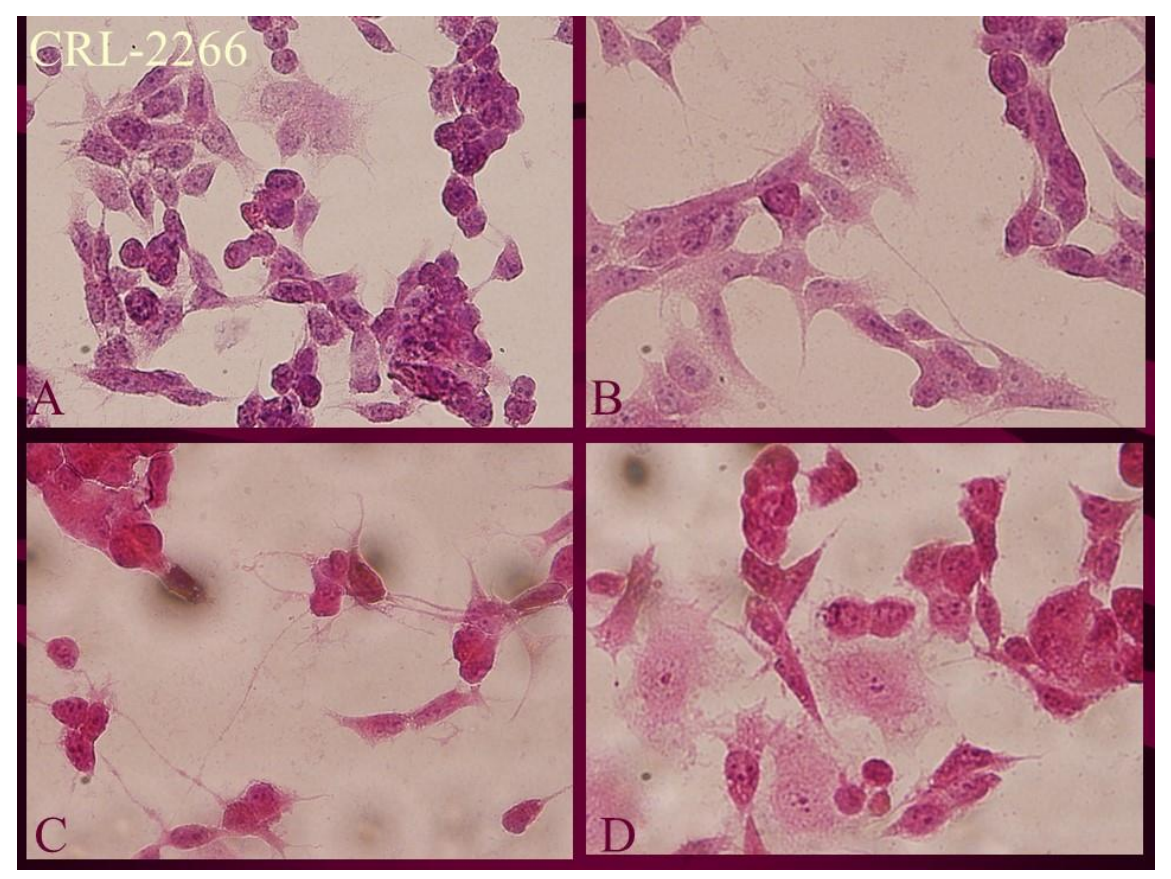

Figure 3 A-D: Morphological analyses utilizing H\&E staining. Female origin human progenitor neuronal cell line (CRL-2266) was evaluated for any disruption in neurite formation after exposure to three different concentrations of thimerosal. The top left image $A$, represents the control cell lines that was not exposed to thimerosal, where as $B, C$ and $D$ represent images of cell lines exposed to $10 \mathrm{mg}, 20 \mathrm{mg}$ and $40 \mathrm{mg}$ of thimerosal, respectively.

Table 3 Neurite formation in the CRL-2266 female neuroblastoma cell line after exposure to three different concentrations of thimerosal. Low (L), Medium (M), and High (H) refer to $10 \mathrm{mg}, 20 \mathrm{mg}$, and $40 \mathrm{mg}$ of thimerosal/L, respectively.

Morphological characters

\begin{tabular}{llllll}
\hline 2266 HE & Chromatolysis & Syncytia & $\begin{array}{l}\text { Axon } \\
\text { Thinning }\end{array}$ & Axon Elongation & Proliferation \\
Control & 4.47 & 1.15 & 18.85 & 1.49 & 77.41 \\
& 2.00 & 1.64 & 19.39 & 3.22 & 52.75 \\
Low & $\mathrm{P}<0.3383$ & $\mathrm{P}<0.6213$ & $\mathrm{P}<0.5477$ & $\mathrm{P}<0.0800$ & $\mathrm{P}<0.4624$ \\
& 2.25 & 1.64 & 20.19 & 2.50 & 39.57
\end{tabular}




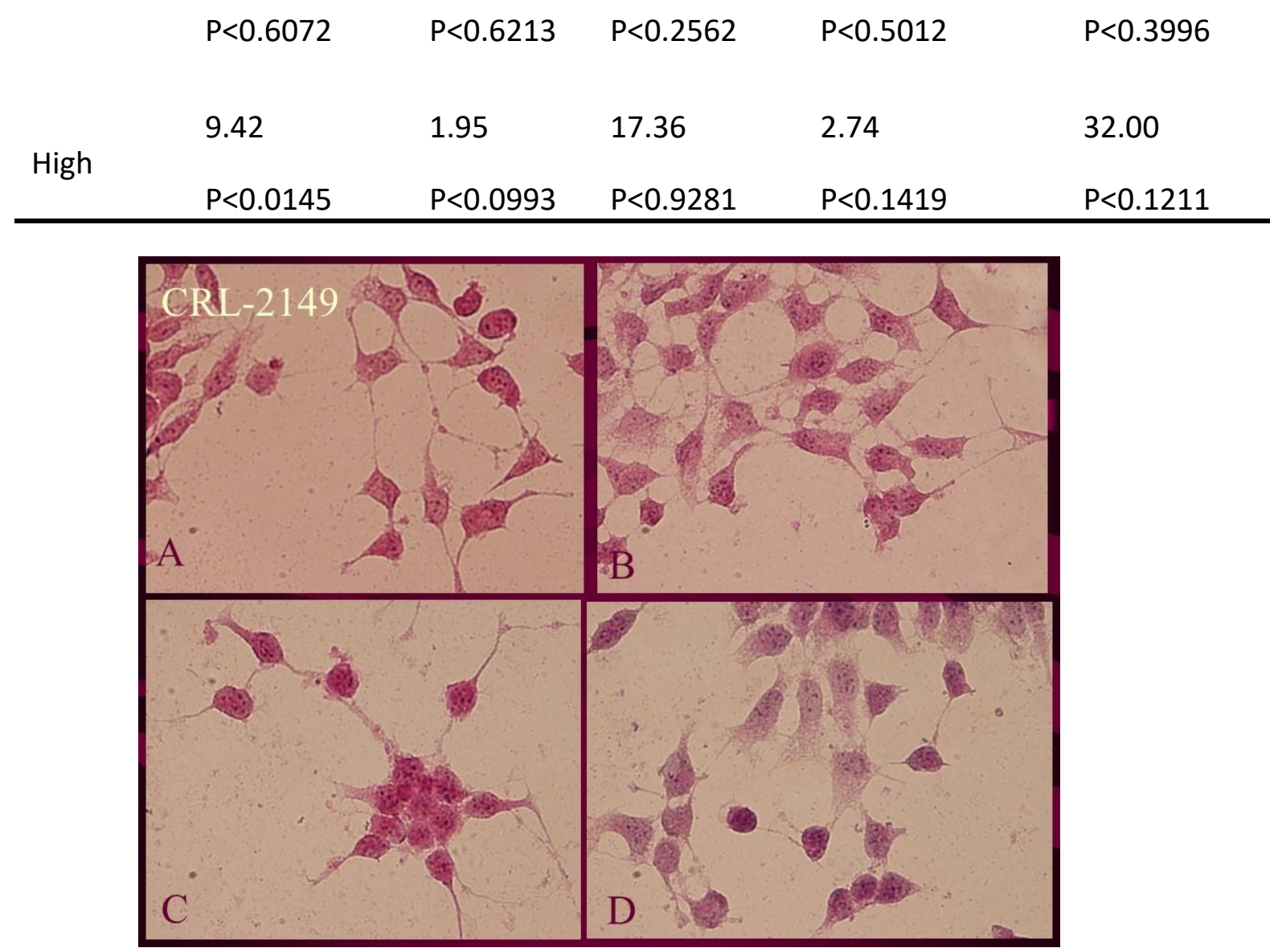

Figure 4 A-D: Morphological analyses utilizing H\&E staining. Female origin human progenitor neuronal cell line (CRL-2149) was evaluated for any disruption in neurite formation after exposure to three different concentrations of thimerosal. The top left image $A$, represents the control cell lines that was not exposed to thimerosal, where as $B, C$ and $D$ represent images of cell lines exposed to $10 \mathrm{mg}, 20 \mathrm{mg}$ and $40 \mathrm{mg}$ of thimerosal, respectively.

Table 4 Neurite formation in female CRL-2149 neuroblastoma cell line after exposure to three different concentrations of thimerosal. Low (L), Medium (M), and High (H) refer to $10 \mathrm{mg}, 20 \mathrm{mg}$, and $40 \mathrm{mg}$ of thimerosal/L, respectively. Significant impairments in cellular proliferation were recorded.

\begin{tabular}{llllll}
\hline $\begin{array}{l}2149 \\
\mathrm{HE}\end{array}$ & Chromatolysis & Syncytia & Axon Thinning & $\begin{array}{l}\text { Axon } \\
\text { Elongation }\end{array}$ & Proliferation \\
\hline Control & 0.65 & 0.65 & 12.67 & 0.95 & 91.64 \\
& & & & & \\
Low & 1.9 & 0 & 15.05 & 1.49 & 60.92 \\
& $\mathrm{P}<0.3739$ & $\mathrm{P}<0.3739$ & $\mathrm{P}<0.5114$ & $\mathrm{P}<0.7040$ & $\mathrm{P}<0.0241$
\end{tabular}


Adv Environ Eng Res 2021; 2(2), doi:10.21926/aeer.2102011

\begin{tabular}{|c|c|c|c|c|c|}
\hline \multirow[t]{2}{*}{ Med } & 1.71 & 1.49 & 18.97 & 2.29 & 59.06 \\
\hline & $P<0.0993$ & $P<0.4766$ & $P<0.2316$ & $P<0.0890$ & $P<0.0289$ \\
\hline \multirow[t]{2}{*}{ High } & 3.28 & 1.29 & 16.74 & 2 & 49.65 \\
\hline & $P<0.0993$ & $P<0.740$ & $P<0.1008$ & $P<0.2080$ & $P<0.0154$ \\
\hline
\end{tabular}

\subsection{Immunological Studies}

When CRL-2267 and CRL-2142 were exposed to 10, 20, and $40 \mathrm{ng} / \mathrm{mL}$ of thimerosal, OXTR expression was downregulated significantly for all concentrations of thimerosal (Table 5) except in CRL-2142 at $10 \mathrm{ng} / \mathrm{mL}$. CRL-2149 showed no change in the expression of OXTR, while CRL-2266 exhibited downregulation of OXTR only at the highest dose of thimerosal (Table 5).

Table 5 The relative degree of expression of OXTR positive neurons in response to exposure to various concentrations of thimerosal. Figures in the same column with different superscripts were significantly different $(p<0.05)$

\begin{tabular}{lllll}
\hline $\begin{array}{l}\text { Concentration } \\
\text { of thimerosal } \\
(\mathrm{mg} / \mathrm{L})\end{array}$ & $\begin{array}{l}\text { CRL-2267 } \\
\text { male }\end{array}$ & $\begin{array}{l}\text { CRL-2142 } \\
\text { male }\end{array}$ & $\begin{array}{l}\text { CRL-2266 } \\
\text { female }\end{array}$ & $\begin{array}{l}\text { CRL-2149 } \\
\text { female }\end{array}$ \\
\hline 0 & $81.4^{\mathrm{a}}$ & $73.6^{\mathrm{a}}$ & $89.5^{\mathrm{a}}$ & $73.3^{\mathrm{a}}$ \\
10 & $51.5^{\mathrm{b}}$ & $51.1^{\mathrm{a}}$ & $84.7^{\mathrm{a}}$ & $73.1^{\mathrm{a}}$ \\
20 & $34.1^{\mathrm{b}}$ & $44.5^{\mathrm{b}}$ & $66.3^{\mathrm{a}}$ & $69.9^{\mathrm{a}}$ \\
40 & $20.5^{\mathrm{b}}$ & $49.8^{\mathrm{b}}$ & $55.8^{\mathrm{b}}$ & $62.8^{\mathrm{a}}$ \\
\hline
\end{tabular}

a: $p$-value with no significant difference compared to the respective controls

b: Significantly different $(p<0.05)$

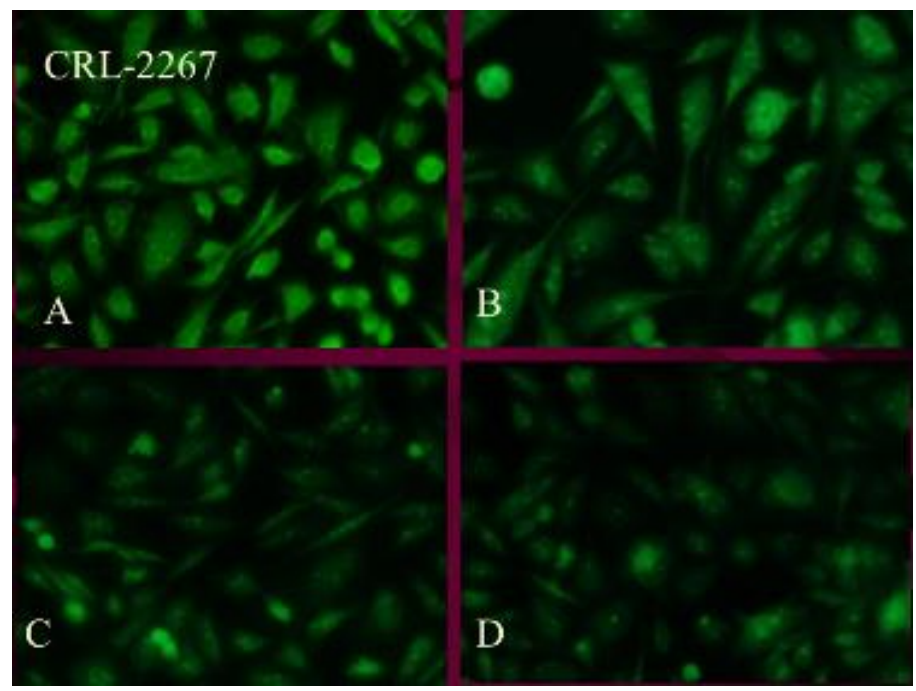


Figure 5 A-D: Immunofluorescence assay utilizing a monoclonal antibody to human oxytocin receptors: Male origins human progenitor neuronal cell line (CRL-2267) was evaluated for oxytocin receptor expression after exposure to three different concentrations of thimerosal. The top left image $A$, represents the control cell lines that was not exposed to thimerosal, whereas $B, C$ and $D$ represent representative images of cell lines exposed to $10 \mathrm{mg}, 20 \mathrm{mg}$ and $40 \mathrm{mg}$ of thimerosal, respectively.

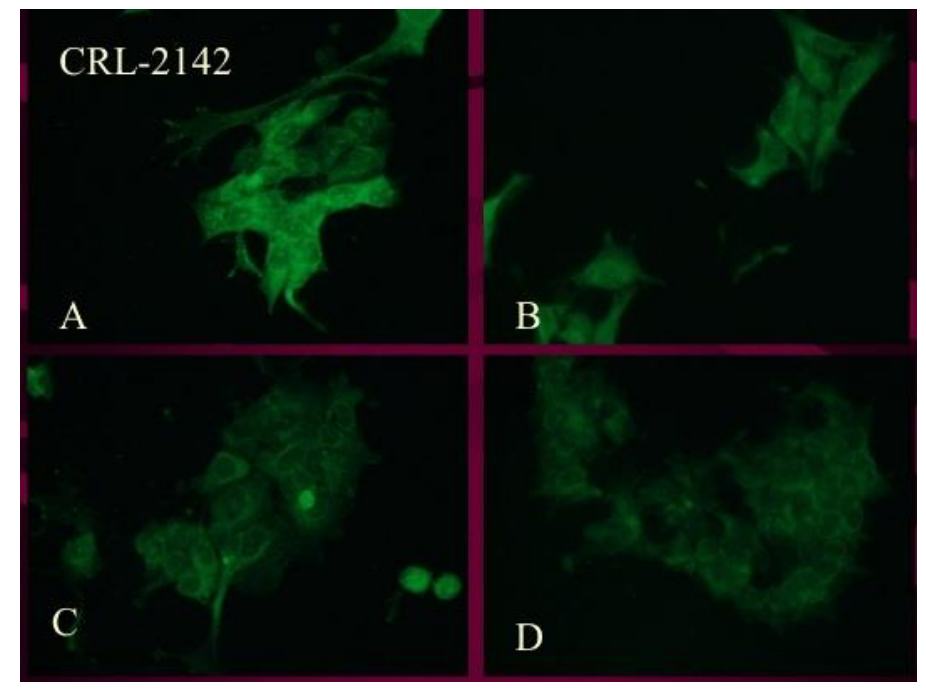

Figure 6 A-D: Immunofluorescence assay utilizing a monoclonal antibody to human oxytocin receptors: Male origins human progenitor neuronal cell line (CRL-2142) was evaluated for oxytocin receptor expression after exposure to three different concentrations of thimerosal. The top left image $A$, represents the control cell lines that was not exposed to thimerosal, whereas $B, C$ and $D$ represent representative images of cell lines exposed to $10 \mathrm{mg}, 20 \mathrm{mg}$ and $40 \mathrm{mg}$ of thimerosal, respectively.

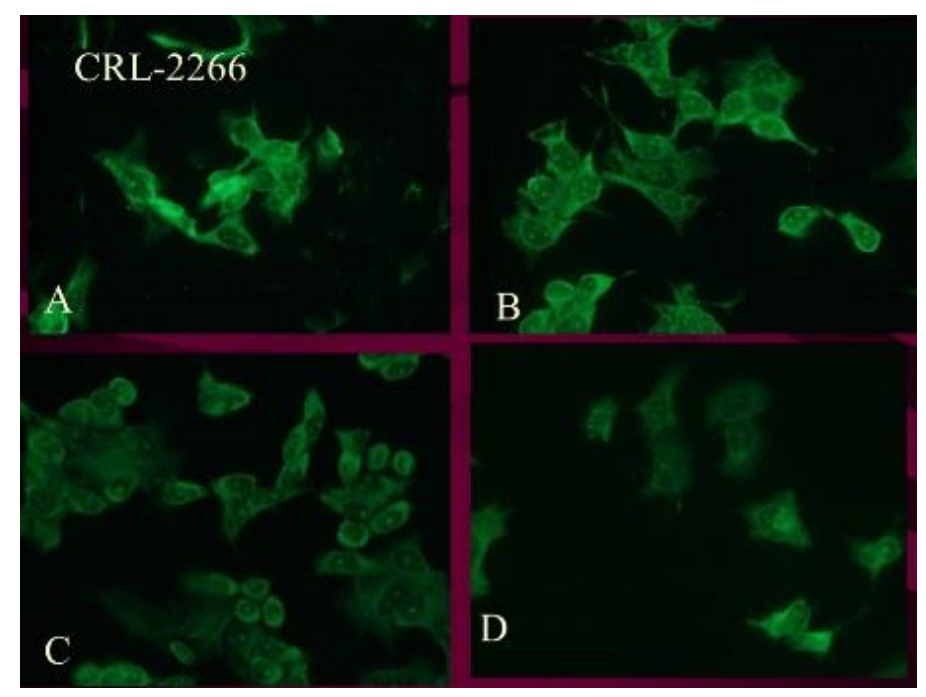

Figure 7 A-D: Immunofluorescence assay utilizing a monoclonal antibody to human oxytocin receptors: Female origins human progenitor neuronal cell line (CRL-2266) was evaluated for oxytocin receptor expression after exposure to three different concentrations of thimerosal. The top left image A, represents the control cell lines that 
was not exposed to thimerosal, whereas $B, C$ and $D$ represent representative images of cell lines exposed to $10 \mathrm{mg}, 20 \mathrm{mg}$ and $40 \mathrm{mg}$ of thimerosal, respectively.

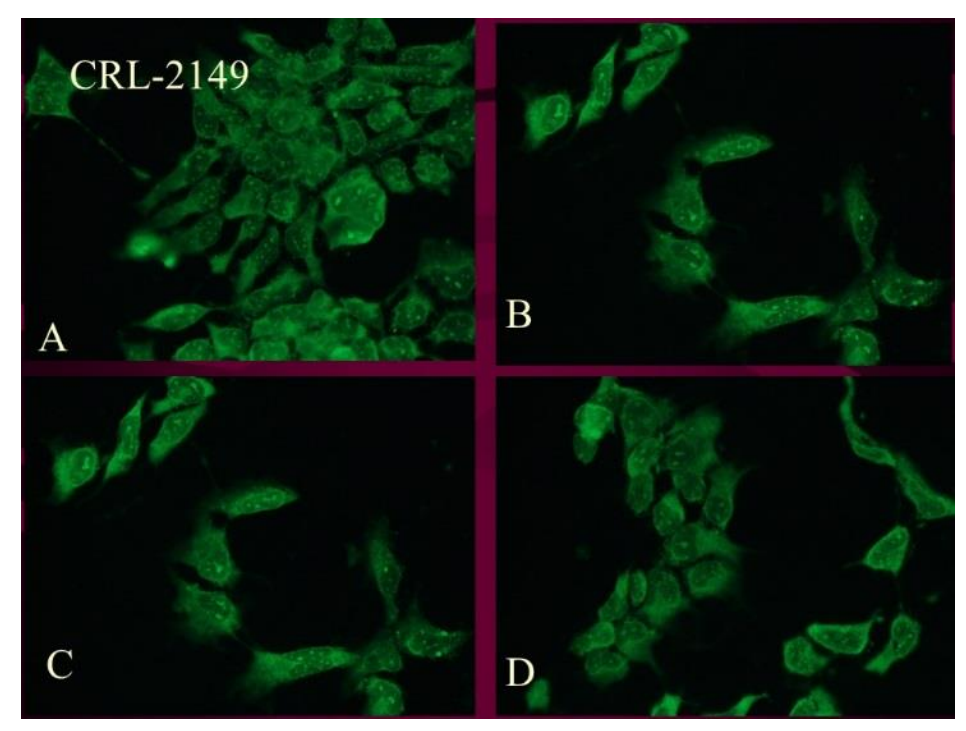

Figure 8 A-D: Immunofluorescence assay utilizing a monoclonal antibody to human oxytocin receptors: Female origins human progenitor neuronal cell line (CRL-2149) was evaluated for oxytocin receptor expression after exposure to three different concentrations of thimerosal. The top left image $A$, represents the control cell lines that was not exposed to thimerosal, whereas $B, C$ and $D$ represent representative images of cell lines exposed to $10 \mathrm{mg}, 20 \mathrm{mg}$ and $40 \mathrm{mg}$ of thimerosal, respectively.

\section{Discussion}

The causes of ASD are generally believed to be either genetic or inheritable, and it is commonly agreed that the etiologies of the syndrome, and its spectrum, lie in the early fetal developmental period. Indeed, a recent, large-scale study confirmed that ASD, most likely, is the spectrum of genetic and environmental factors that a fetus experiences during prenatal development [7]. The most severe outcome appears to correlate with adverse effects when a fetus is exposed to certain chemicals during early development [15].

The etiology of RA, where a child shows normal development and then begins to lose previously acquired skills over a short time frame, is a conundrum and remains difficult to explain [1-5]. RA is a devastating disorder affecting children between the ages of 1-3 years, characterized by the loss of social interaction and abilities to communicate following otherwise healthy development [16]. In the Diagnostic and Statistical Manual of Mental Disorders, Fifth Edition (DSM-5), childhood disintegrative disorder, along with other types of autism, are merged into a single spectrum called autism spectrum disorder (ASD). Childhood disintegrative disorder has a relatively late onset and is characterized by the regression of previously acquired social, language, and motor skills. Some parents believe that vaccines containing thimerosal may be culpable. Videotape analysis has recently helped document the deterioration of language skills in children with regressive autism. Interestingly, one study showed that a group of infants, who were later diagnosed with RA, had higher than average language skills at one year of age that fell to well-below average when they were two years old [17]. 
RA also has a large spectrum resulting in mild to severe outcomes. It has been reported that approximately $30 \%$ of autistic individuals experience a "regressive" onset between the ages of 18 and 24 months [4]. There are also well-documented studies that completely refute the notion that thimerosal, or vaccines containing the preservative, plays any role in the development of RA. Unfortunately, many of the scientific inquiries have become politicized [18].

Here, we evaluated the effects of thimerosal on developing human neurons in vitro at higher concentrations than would normally be experienced after administration to an infant, toddler, and young adult following single vaccination. However, these same concentrations might conceivably occur following concurrent vaccinations and other treatments, such as those for skin test antigens, and nasal and ophthalmic preparations. Our results clearly showed significant morphological disruptions in neurite formation after exposure to the doses of thimerosal provided. Notably, we also observed a male gender bias in our study that determined undifferentiated male neurons to be significantly more vulnerable to thimerosal than undifferentiated female neurons. A male gender bias in ASD is well-documented, and our observations may explain this susceptibility to thimerosal [19].

Our study also revealed another mechanism by which children with RA lose social connection, probably due to the downregulation of the oxytocin receptor, as determined by the immunofluorescent assay. Again, male developing neurons showed greater susceptibility to thimerosal than those of females [19]. Among its many roles in the brain, oxytocin influences communication and social bonding [5].

Tammimies reported that RA occurs in approximately one-third of children with ASD [2]. Therefore, it appears that RA is more common than previously assumed. The age at which this disease manifests is variable, but it is typically seen after three years of normal development [1-4]. Surprisingly, the regression can be so fast that the child may be aware of it, and during the early stages of onset, may even ask what is happening to them, similar to the onset of Alzheimer's disease [20]. The most common and distinct feature of this disease is that the skills they already had acquired are lost [16].

The neuropeptide oxytocin and its receptor play an important role in the regulation of social functioning in ASD. Produced in the hypothalamus, this neurotransmitter is involved in various social behaviors, including mammalian labor and nursing, maternal conduct, bonding, and social recognition and reward [15, 21]. It binds to oxytocin receptors expressed in neurons across the brain, including the amygdala, olfactory bulb, nucleus accumbens, brainstem, septum, and ventromedial hypothalamus (Figure 9) [22]. Studies in mice, where the oxytocin receptor gene had been deleted, revealed deficits in social interaction, including spending more time alone and self-grooming, compared to their wild-type counterparts $[23,24]$. These behaviors are like those of individuals with ASD, suggesting that alterations in the oxytocin receptor during fetal development may explain some of the social deficits characteristic of individuals with ASD [25, 26]. Moreover, decreased flow of oxytocin between mother and fetus has been associated with autistic-like characteristics in adulthood [25]. 


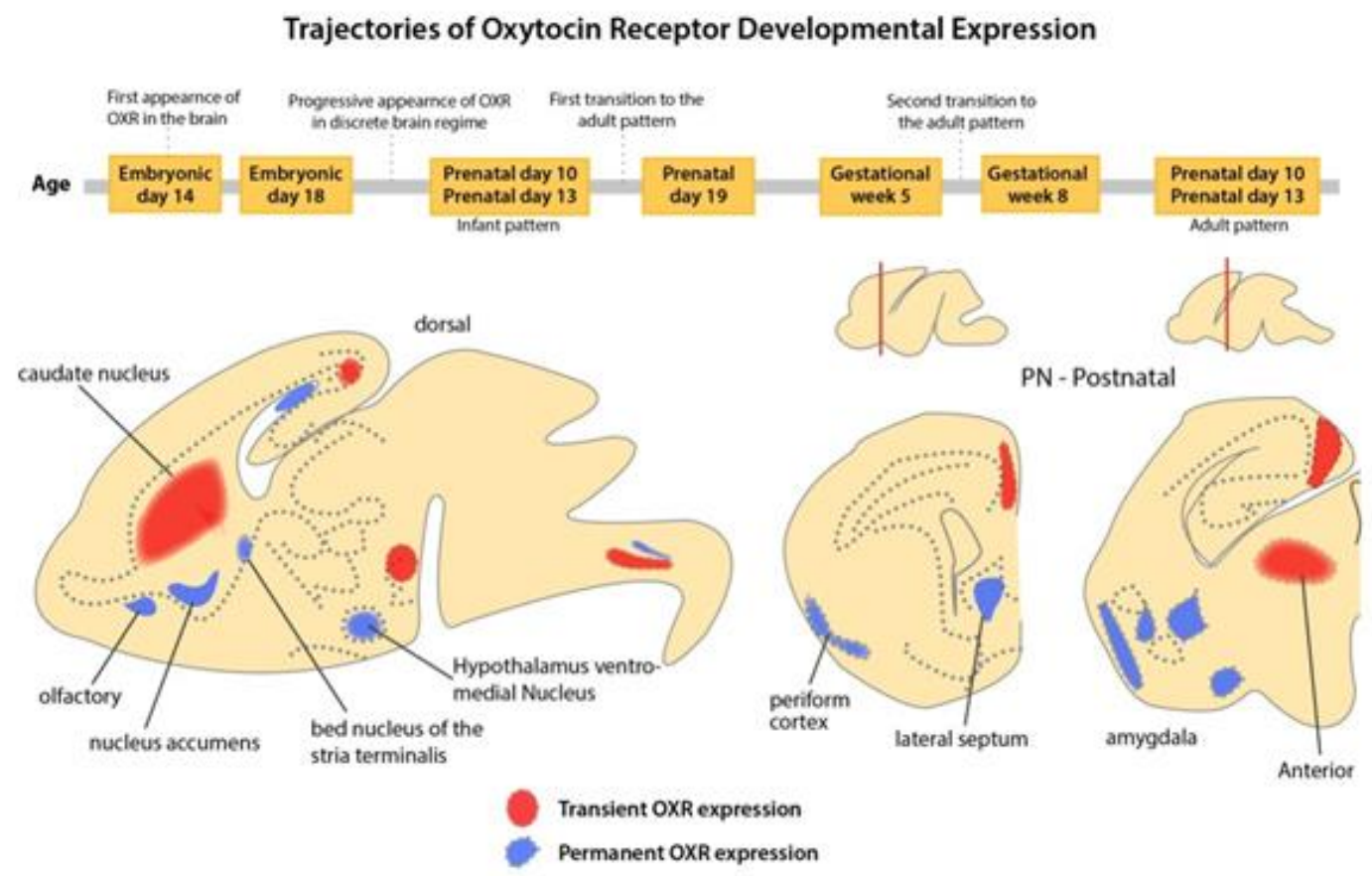

Figure 9 Developmental trajectories of oxytocin receptor in the rat brain. Top: Schematic of the time course of oxytocin receptor expression in the developing brain. Bottom: Oxytocin receptor expression in the infant-brain around prenatal period (P10-P13). Regions in which transient oxytocin receptor expression is observed are colored in red. Regions in which oxytocin receptor expression is maintained to adulthood are colored in blue (adapted from [22]).

\subsection{Role of Blood-Brain Barrier in Development of RA}

Although thimerosal has been removed from some childhood vaccines in the United States (US), it is still used in many vaccines in developing nations [19]. This is mainly due to the shortage or absence of refrigeration. In the US, thimerosal is still used in the meningococcal vaccine, which is recommended for young adults going for higher education after high school. Thimerosal was also used in the tetanus-toxoid vaccine until very recently, and it is given to individuals of all ages [27]. Additionally, in the US, over half of influenza-vaccine doses ( $>75$ million annually) still contain thimerosal [9].

Whether thimerosal exposure impacts childhood development remains controversial and has been politicized [18]. Boom et al. have shown that thimerosal is safe for use in children [28], whereas Geier et al. support the claim that it is unsafe for children [29]. Many studies support both views [9, 11-13, 30]. The CDC emphasizes that thimerosal is safe [29]. Numerous well-designed studies suggest that thimerosal can penetrate the BBB and that inorganic mercury is released within cells. Mercury has been detected in the brain of autopsied children exposed to thimerosal via vaccines or by accidental exposure and, in some reports, when applied on the skin to treat certain dermatologic conditions. Mercury-based compounds would be undeniably neurotoxic if they were to breach the BBB. However, numerous case-control and cohort studies conducted on a variety of populations have validated the notion that thimerosal exposure increased the risk of ASD or RA development 
[31]. If thimerosal had penetrated a child's brain after crossing the BBB and had metabolized or degraded to inorganic mercury, its toxicity would have had serious consequences. Therefore, it is unlikely that thimerosal can cross the BBB and invade the brain in normal healthy children [31]. We speculate that other factors make some children susceptible to thimerosal by allowing the neurotoxin to penetrate the BBB [7].

The BBB is a semipermeable lining, composed of tightly packed endothelial cells that separate the brain from the circulatory system and protect the central nervous system (CNS). It filters out potentially harmful toxins and bacteria and allows only essential molecules to pass. This barrier protects the brain by maintaining a constant environment and preventing foreign and harmful substances from entering [32]. The brain is composed of an extremely complex network of neurons, astrocytes, microglial cells, and endothelial cells. To function efficiently, it is crucial to maintain a stable environment in the brain for messages to be properly exchanged (Figure 10). Besides protecting from harmful substances, the BBB also protects the CNS from hormones and neurotransmitters that function in other parts of the body [33]. The integrity of the BBB can be altered by several factors such as exposure to radiation, microwaves, infections, and hypertension. Research suggests that a weakened BBB could precede, accelerate, or even contribute to numerous neurodegenerative disorders. A "leaky BBB" can result from an underlying inflammation.
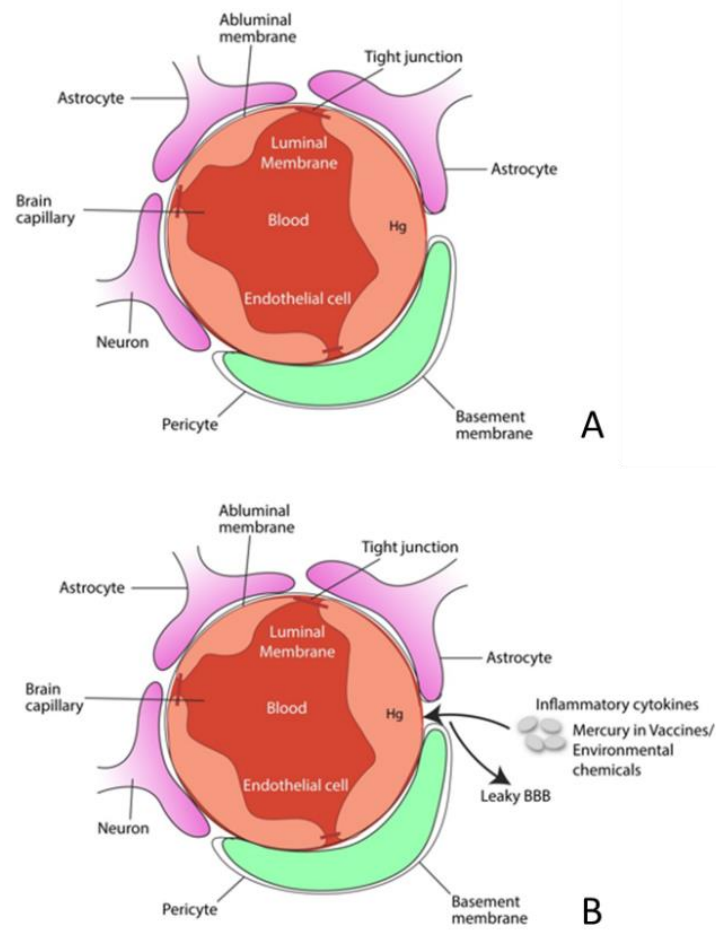

Figure 10 Mechanism of cytokine-mediated leakiness of the blood-brain barrier (BBB). A: Normal BBB; and B: Leaky BBB, induced by inflammatory cytokines, particularly IL-6 (adapted from [22]).

Several inflammatory molecules have been shown to increase in the brain and cerebrospinal fluid of many ASD individuals, including IL-1 $\beta$, IL-6, TNF, MCP-1, and CCL8 (IL-8) [33-35]. Plasma levels of IL-1 $\beta$, IL-6, and IL-8 were high in children with ASD and correlated with regressive autism, impaired communication, and aberrant behavior [36, 37]. The evidence of increased neuroinflammation in 
brain specimens obtained from subjects with ASD showing increased infiltration of lymphocytes and macrophages validates a leaky BBB. For example, Vargas et al. [38] analyzed autopsied brain tissues from the cerebellum, mid-frontal, and the cingulate gyrus from 11 patients with autism, freshfrozen tissues from seven patients, and cerebrospinal fluid [CSF] from six living autistic patients for cytokine protein profiling. They showed active neuroinflammation in the cerebral cortex, white matter, and cerebellum of autistic patients [39]. Similarly, when a neonate or a toddler is exposed to thimerosal, or other neurotoxins, during a period when the BBB is transiently leaky due to an underlying factor (i.e., inflammatory cytokines), it may increase their susceptibility to neurodegeneration. A potential solution to prevent this possibility is to measure the levels of cofactors that make a child vulnerable to vaccines or neurotoxins. A simple test is to check for fever at the time of vaccination or use a lateral flow assay (LFA) in all children younger than one year before administration of thimerosal-containing biologics. Any child showing an elevated level of proinflammatory cytokines, i.e., IL-6 or TNF- $\alpha$ should be vaccinated later, when the child reaches normal levels of these two cytokines. The LFAs are easy to design and are inexpensive to manufacture and administer.

\section{Conclusion}

From our study, we conclude that thimerosal-containing vaccines may contribute to RA but only in extreme circumstances when the BBB is leaky during vaccination. If human developing neurons are exposed to thimerosal in vitro, where there is no BBB to protect the brain, it significantly affects neurite formation and downregulates oxytocin receptor expression. The adverse effects of thimerosal are more significant on neurons of male origin than of female origin. We speculate that the reported adverse effects of exposure to thimerosal-containing vaccines is a rare event and is most likely due to a transient leaky BBB. A solution to this issue has been presented.

\section{Author Contributions}

OB initially conceived the idea, designed, and planned the study. The experiments were further refined by NS. GG, OB and PP who significantly contributed in performing the experiments. All authors significantly contributed in preparation of the manuscript. NS and EM contributed in preparation and refinement of the manuscript.

\section{Funding}

Part of the studies were supported from a grant from SC EPSCoR Award Number SRP 18-SR03 to OB.

\section{Competing Interests}

This work has not been published previously. It is not under review for publication anywhere else. It is approved by all authors, and that, if accepted, it will not be published elsewhere in the same form, in English or in any other language, including electronically without the written consent of the copyright-holder. 


\section{References}

1. Boterberg S, Charman T, Marschik PB, Bölte S, Roeyers H. Regression in autism spectrum disorder: A critical overview of retrospective findings and recommendations for future research. Neurosci Biobehav Rev. 2019; 102: 24-55.

2. Tammimies K. Genetic mechanisms of regression in autism spectrum disorder. Neurosci Biobehav Rev. 2019; 102: 208-220.

3. Downs R, Perna J, Vitelli A, Cook D, Dhurjati P. Model-based hypothesis of gut microbe populations and gut/brain barrier permeabilities in the development of regressive autism. Med Hypothese. 2014; 83: 649-655.

4. Ozonoff S, losif AM. Changing conceptualizations of regression: What prospective studies reveal about the onset of autism spectrum disorder. Neurosci Biobehav Rev. 2019; 100: 296-304.

5. Sealey LA, Hughes BW, Steinemann A, Pestaner JP, Pace DG, Bagasra O. Role of environmental factors in autism development and male bias: Neuromodifying effects of fragrance. Environ Res. 2015; 142: 731-738.

6. Hughes BW, Addanki KC, Sriskanda AN, McLean E, Bagasra O. Infectivity of immature neurons to Zika virus: A link to congenital Zika syndrome. EBioMedicine. 2016; 10: 65-70.

7. Bagasra O, Heggen C. Autism and environmental factors. Hoboken: Wiley Online Library; 2018.

8. Frye RE, Cakir J, Rose S, Delhey L, Bennuri SC, Tippett M, et al. Early life metal exposure dysregulates cellular bioenergetics in children with regressive autism spectrum disorder. Transl Psychiatry. 2020; 10: 223.

9. Kern JK, Geier DA, Homme KG, Geier MR. Examining the evidence that ethylmercury crosses the blood-brain barrier. Environ Toxicol Pharmacol. 2020; 74: 103312.

10. Selig KM. Alkyl mercuric sulphur compound and process of producing it. Washington, DC: United States Patent; 1928; US1672615A.

11. Baker JP. Mercury, vaccines, and autism: One controversy, three histories. Am J Public Health. 2008; 98: 244-253.

12. DeStefano F, Bodenstab HM, Offit PA. Principal controversies in vaccine safety in the United States. Clin Infect Dis. 2019; 69: 726-731.

13. Gadad BS, Li W, Yazdani U, Grady S, Johnson T, Hammond J, et al. Administration of thimerosalcontaining vaccines to infant rhesus macaques does not result in autism-like behavior or neuropathology. Proc Natl Acad Sci U S A. 2015; 112: 12498-12503.

14. Dozmorov MG, Bilbo SD, Kollins SH, Zucker N, Do EK, Schechter JC, et al. Associations between maternal cytokine levels during gestation and measures of child cognitive abilities and executive functioning. Brain Behav Immun. 2018; 70: 390-397.

15. Sealey LA, Hughes BW, Sriskanda AN, Guest JR, Gibson AD, Johnson-Williams L, et al. Environmental factors in the development of autism spectrum disorders. Environ Int. 2016; 88: 288-298.

16. Mughal S, Faizy RM, Saadabadi A, Doerr C. Autism Spectrum Disorder (Nursing). Treasure Island, FL: StatPearls Publishing; 2021.

17. Werner $E$, Dawson $G$. Validation of the phenomenon of autistic regression using home videotapes. Arch Gen Psychiatry. 2005; 62: 889-895.

18. Lillvis DF, Kirkland A, Frick A. Power and persuasion in the vaccine debates: An analysis of political efforts and outcomes in the United States, 1998-2012. Milbank Q. 2014; 92: 475-508. 
19. Kern JK, Geier DA, Homme KG, King PG, Bjørklund G, Chirumbolo S, et al. Developmental neurotoxicants and the vulnerable male brain: A systematic review of suspected neurotoxicants that disproportionally affect males. Acta Neurobiol Exp. 2017; 77: 269-296.

20. Bigham M, Copes R. Thiomersal in vaccines. Drug Saf. 2005; 28: 89-101.

21. Ferguson JN, Aldag JM, Insel TR, Young LJ. Oxytocin in the medial amygdala is essential for social recognition in the mouse. J Neurosci. 2001; 21: 8278-8285.

22. Grinevich V, Desarménien MG, Chini B, Tauber M, Muscatelli F. Ontogenesis of oxytocin pathways in the mammalian brain: Late maturation and psychosocial disorders. Front Neuroanat. 2015 Jan 20; 8: 164.

23. Amico JA, Mantella RC, Vollmer RR, Li X. Anxiety and stress responses in female oxytocin deficient mice. J Neuroendocrinol. 2004; 16: 319-324.

24. Kavaliers M, Ågmo A, Choleris E, Gustafsson JÅ, Korach KS, Muglia LJ, et al. Oxytocin and estrogen receptor $\alpha$ and $\beta$ knockout mice provide discriminably different odor cues in behavioral assays. Genes Brain Behav. 2004; 3: 189-195.

25. Zhang R, Zhang HF, Han JS, Han SP. Genes related to oxytocin and arginine-vasopressin pathways: Associations with autism spectrum disorders. Neurosci Bull. 2017; 33: 238-246.

26. Kirsch P. Oxytocin in the socioemotional brain: Implications for psychiatric disorders. Dialogues Clin Neurosci. 2015; 17: 463-476.

27. Institute of Vaccine Safety. Johns Hopkins Bloomberg School of Public Health. Thimerosal Content in Some US Licensed Vaccines [Internet]. Baltimore, MD: Institute of Vaccine Safety. Johns Hopkins Bloomberg School of Public Health; 2018 [cited 2019 December 2nd]. Available from: https://www.vaccinesafety.edu/thi-table.htm.

28. Boom JA, Cunningham RM, McGee LU. Vaccine myths: Setting the record straight. J Fam Strenghts. 2018; 18: 13.

29. Geier DA, King PG, Hooker BS, Dórea JG, Kern JK, Sykes LK, et al. Thimerosal: Clinical, epidemiologic and biochemical studies. Clin Chim Acta. 2015; 444: 212-220.

30. Spencer JP, Pawlowski RH, Thomas S. Vaccine adverse events: Separating myth from reality. Am Fam Physician. 2017; 95: 786-794.

31. Gołoś A, Lutyńska A. Thiomersal-containing vaccines-a review of the current state of knowledge. Przegl Epidemiol. 2015; 69: 59-64.

32. Daneman R, Prat A. The blood-brain barrier. Cold Spring Harb Perspect Biol. 2015; 7: a020412.

33. Li X, Chauhan A, Sheikh AM, Patil S, Chauhan V, Li XM, et al. Elevated immune response in the brain of autistic patients. J Neuroimmunol. 2009; 207: 111-116.

34. Zimmerman AW, Jyonouchi H, Comi AM, Connors SL, Milstien S, Varsou A, et al. Cerebrospinal fluid and serum markers of inflammation in autism. Pediatr Neurol. 2005; 33: 195-201.

35. Tsilioni I, Taliou A, Francis K, Theoharides TC. Children with autism spectrum disorders, who improved with a luteolin-containing dietary formulation, show reduced serum levels of TNF and IL-6. Transl Psychiatry. 2015; 5: e647.

36. Hagberg $\mathrm{H}$, Mallard C. Effect of inflammation on central nervous system development and vulnerability. Curr Opin Neurol. 2005; 18: 117-123.

37. Ashwood P, Krakowiak P, Hertz-Picciotto I, Hansen R, Pessah I, Van de Water J. Elevated plasma cytokines in autism spectrum disorders provide evidence of immune dysfunction and are associated with impaired behavioral outcome. Brain Behav Immun. 2011; 25: 40-45.

38. Vargas DL, Nascimbene C, Krishnan C, Zimmerman AW, Pardo CA. Neuroglial activation and 
neuroinflammation in the brain of patients with autism. Ann Neurol. 2005; 57: 67-81.

39. Napolioni V, Ober-Reynolds B, Szelinger S, Corneveaux JJ, Pawlowski T, Ober-Reynolds S, et al. Plasma cytokine profiling in sibling pairs discordant for autism spectrum disorder. J Neuroinflammation. 2013; 10: 813.

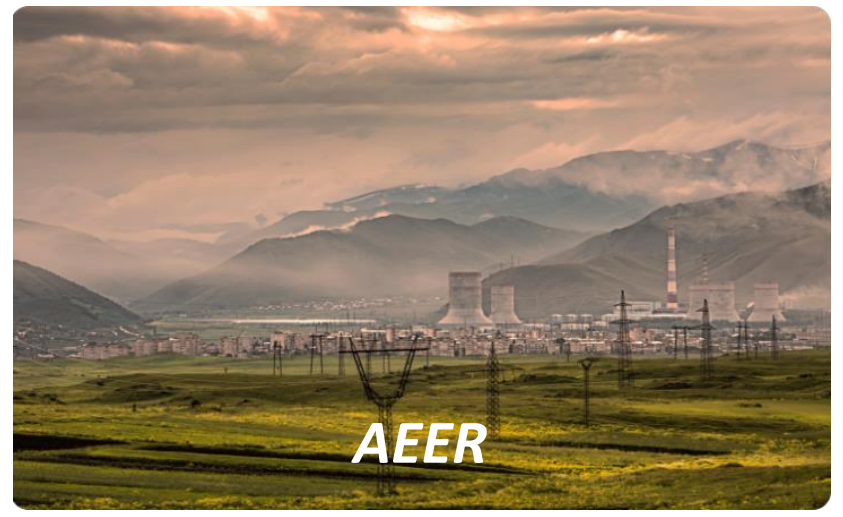

Enjoy AEER by:

1. Submitting a manuscript

2. Joining in volunteer reviewer bank

3. Joining Editorial Board

4. Guest editing a special issue

For more details, please visit:

http://www.lidsen.com/journals/aeer 